Article

\title{
Coelastrella terrestris for Adonixanthin Production: Physiological Characterization and Evaluation of Secondary Carotenoid Productivity
}

\author{
Philipp Doppler ${ }^{1}\left(\mathbb{D}\right.$, Ricarda Kriechbaum ${ }^{1}$, Maria Käfer ${ }^{1}$, Julian Kopp ${ }^{1}$ (D), Daniel Remias ${ }^{2}$ (D) \\ and Oliver Spadiut $1, * \mathbb{D}$ \\ 1 Research Division Biochemical Engineering, Institute of Chemical, Environmental and Bioscience \\ Engineering, TU Wien, Gumpendorfer Strasse 1a, 1060 Vienna, Austria; philipp.doppler@tuwien.ac.at (P.D.); \\ ricarda.kriechbaum@tuwien.ac.at (R.K.); maria.kaefer@students.boku.ac.at (M.K.); \\ julian.kopp@tuwien.ac.at (J.K.) \\ 2 School of Engineering, University of Applied Sciences Upper Austria, Stelzhamerstr. 23, 4600 Wels, Austria; \\ daniel.remias@fh-wels.at \\ * Correspondence: oliver.spadiut@tuwien.ac.at; Tel.:+43-1-58801-166473
}

check for updates

Citation: Doppler, P.; Kriechbaum, R.; Käfer, M.; Kopp, J.; Remias, D.; Spadiut, O. Coelastrella terrestris for Adonixanthin Production:

Physiological Characterization and Evaluation of Secondary Carotenoid Productivity. Mar. Drugs 2022, 20, 175. https://doi.org/10.3390/ md20030175

Academic Editor: Céline Laroche

Received: 12 January 2022

Accepted: 25 February 2022

Published: 26 February 2022

Publisher's Note: MDPI stays neutral with regard to jurisdictional claims in published maps and institutional affiliations.

Copyright: (C) 2022 by the authors. Licensee MDPI, Basel, Switzerland. This article is an open access article distributed under the terms and conditions of the Creative Commons Attribution (CC BY) license (https:// creativecommons.org/licenses/by/ $4.0 /)$.

\begin{abstract}
A novel strain of Coelastrella terrestris (Chlorophyta) was collected from red mucilage in a glacier foreland in Iceland. Its morphology showed characteristic single, ellipsoidal cells with apical wart-like wall thickenings. Physiological characterization revealed the presence of the rare keto-carotenoid adonixanthin, as well as high levels of unsaturated fatty acids of up to $85 \%$. Initial screening experiments with different carbon sources for accelerated mixotrophic biomass growth were done. Consequently, a scale up to $1.25 \mathrm{~L}$ stirred photobioreactor cultivations yielded a maximum of $1.96 \mathrm{mg} \cdot \mathrm{L}^{-1}$ adonixanthin in free and esterified forms. It could be shown that supplementing acetate to the medium increased the volumetric productivity after entering the nitrogen limitation phase compared to autotrophic control cultures. This study describes a promising way of biotechnological adonixanthin production using Coelastrella terrestris.
\end{abstract}

Keywords: microalgae; stirred photobioreactor; nutrient starvation; osmotic stress; unsaturated fatty acids; astaxanthin; canthaxanthin

\section{Introduction}

Microalgae belong to the oldest forms of life on earth and are genetically highly diverse [1]. They are the largest group of microorganisms capable of photosynthesis, which enables them to harvest light energy for fixation of inorganic carbon dioxide $\left(\mathrm{CO}_{2}\right)$ for biomass growth [2]. For the production of microalgal biomass, many different photobioreactor (PBR) designs have been developed [3]. Additionally, different strategies of autotrophic, mixotrophic and heterotrophic cultivation regimes were introduced for enhanced biomass production $[4,5]$. For mixotrophic cultures, pentoses, hexoses, or other substrates were reported to boost growth of numerous microalgal species [6,7].

The natural product portfolio of microalgae is extremely versatile. Whole biomass can be used as a human nutraceutical food source since it is rich in vitamins, essential amino acids and polyunsaturated fatty acids (FA) [8]. It can be processed for intended production of next-generation biofuels, or individual bioactive compounds for pharmaceutical applications can be extracted $[9,10]$. An abundant group of these compounds are pigments, namely chlorophyll (Chl) and carotenoids [11]. Carotenoids are polyunsaturated tetraterpenoids with about 850 different derivatives [12]. The carotenoids produced by microalgae consist of carotenes and xanthophylls. The primary carotenoids (PC) of the chloroplasts, such as $\beta$-carotene, lutein or zeaxanthin, are essential for photosynthesis and have industrial relevance in cosmetics and pharmaceutics $[13,14]$. 
Secondary carotenoids (SC) can accumulate in certain cell compartments, e.g., cytosolic lipid bodies or in plastoglobuli after stress induction $[15,16]$. The most important and effective stress stimuli are excess of light, nutrient starvation, temperature and $\mathrm{pH}$ shifts or osmotic pressure $[17,18]$. The most well-known SC is astaxanthin, a natural pigment used as colorant in food production, in cosmetics or as feed additive for aquaculture [19]. Astaxanthin has the highest antioxidant capacity of all carotenoids [20]. It is produced during aplanospore formation of the prominent green alga Haematococcus lacustris, commonly known as Haematococcus pluvialis. Another microalgal SC with high potential in industry is adonixanthin [12]. It is a unique keto-carotenoid containing two polar ionone rings. Compared to the astaxanthin structure, only one of the ionone rings carries a ketone. This causes polarity and could result in stronger protective effects than astaxanthin [21]. Adonixanthin was reported to show very promising results in anti-tumor and anti-cancer treatment and protection against brain damage induced by cerebral hemorrhage [21,22]. However, studies on the biotechnological production of adonixanthin in algae are scarce.

In this study a novel strain of the green alga Coelastrella terrestris (Chlorophyta, Scenedesmaceae) was characterized. Strain WP154.1 was sampled in Iceland and isolated from red mucilage in a small brook close to a glacier. The species was first described by Reisigl (1964) in the Austrian Alps and initially named Scotiella terrestris [23]. In recent years, several members of the genus Coelastrella were screened for pigment and lipid production. Hu et al. (2013) identified the pigment composition of the thermotolerant strain Coelastrella sp. F50 grown in glass bottles [24]; Minhas et al. (2016) identified five Coelastrella sp. isolates and conducted Erlenmeyer flask cultures for pigment and lipid measurements [25]; Wang et al. (2019) did phylogenetic studies and described a new species of the genus Coelastrella [26]; Goecke et al. (2020) published the FA pattern and qualitative pigment composition of their strain grown in a $250 \mathrm{~mL}$ tubular PBR [27]; and Zaytseva et al. (2021) reported on their new strain C. rubescens NAMSU R1 and identified the carotenoids present after Erlenmeyer flask cultivations [28]. However, the only report on adonixanthin accumulation of Coelastrella was published by Minyuk et al. (2017) [29]. The group did C. rubescens Erlenmeyer flask experiments with inorganic $\mathrm{CO}_{2}$ or organic acetate as a carbon source (C-source) in combination with low-pH stress for SC production. However, they did not find any correlation of C-source and SC productivity, and mainly focused on the identification of the accumulated SC and lipids rather than the potential of biotechnological production.

Our goal was to characterize strain C. terrestris WP154.1 in terms of morphology and physiology, pigment content and fatty acid composition. The potential of this novel strain as alternative source of natural pigments, especially adonixanthin, was investigated for future biotechnological production. Thus, we performed screening experiments to find adequate $\mathrm{C}$-sources for enhanced mixotrophic biomass formation compared to autotrophic growth. Subsequently, this knowledge was used for scaling up to 1.25 L PBR experiments. This study describes a biotechnological adonixanthin production process by $C$. terrestris.

\section{Results}

\subsection{Morphological and Physiological Characterization of C. terrestris WP154.1 2.1.1. Morphology}

Light microscopical observations showed the unicellular alga in its characteristic shape (Figure 1). Single cells of C. terrestris WP154.1 appeared ellipsoidal or lemon-shaped, both apices showed wart-like wall thickenings. Their cell size ranged between 9 to $13 \mu \mathrm{m}$ length and 7 to $10 \mu \mathrm{m}$ width (Figure 1a). Maturing cells enlarged in size underwent asexual reproduction by autosporulation (Figure $1 \mathrm{~b}, \mathrm{c}$ ). Figure $1 \mathrm{~d}$ shows the division into four daughter cells in planar arrangement, but also eight or more daughter cells were observed. By cell wall rupture, the daughter cells with a chloroplast and a prominent pyrenoid were released (Figure 1e). Due to experimental nutrient starvation, the aged cells accumulated SC and appeared in orange-reddish color (Figure 1f). 
(a)

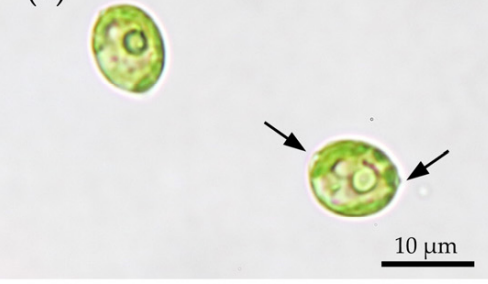

(d)

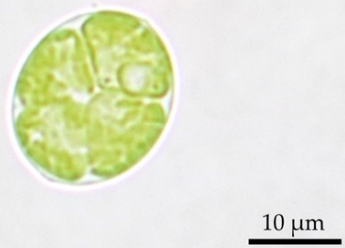

(b)

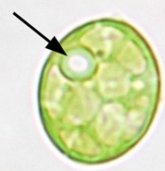

$10 \mu \mathrm{m}$

(e)

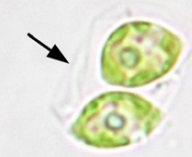

(c)
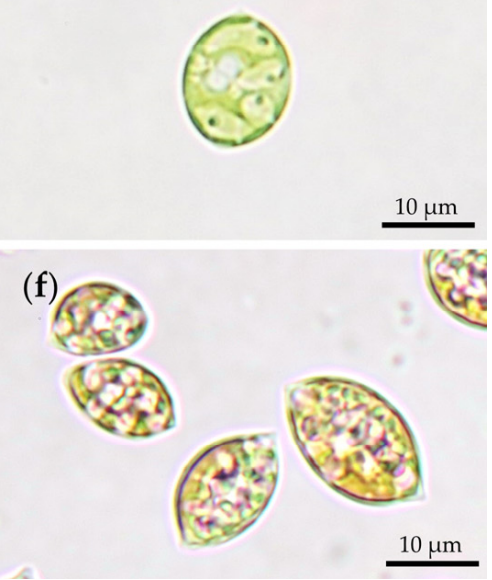

Figure 1. Light microscopical observation of C. terrestris WP154.1 at different cell stages. (a) Single lemon-shaped cells with definite chloroplast and pyrenoid, arrows: wart-like wall thickenings; $(\mathbf{b}, \mathbf{c})$ swollen cells before cell division, arrow: pyrenoid; (d) four daughter cells after cell division in planar arrangement; (e) two daughter cells within old cell wall of mother cell, arrow: cell wall of mother cell; (f) stressed cells with accumulated secondary carotenoids, indicated by their orange coloration.

\subsubsection{Pigment Composition}

To identify the molecules which were responsible for WP154.1's coloration, orange colored biomass was treated for pigment extraction and identification. The chromatogram after HPLC separation of the extract is shown in Figure 2.

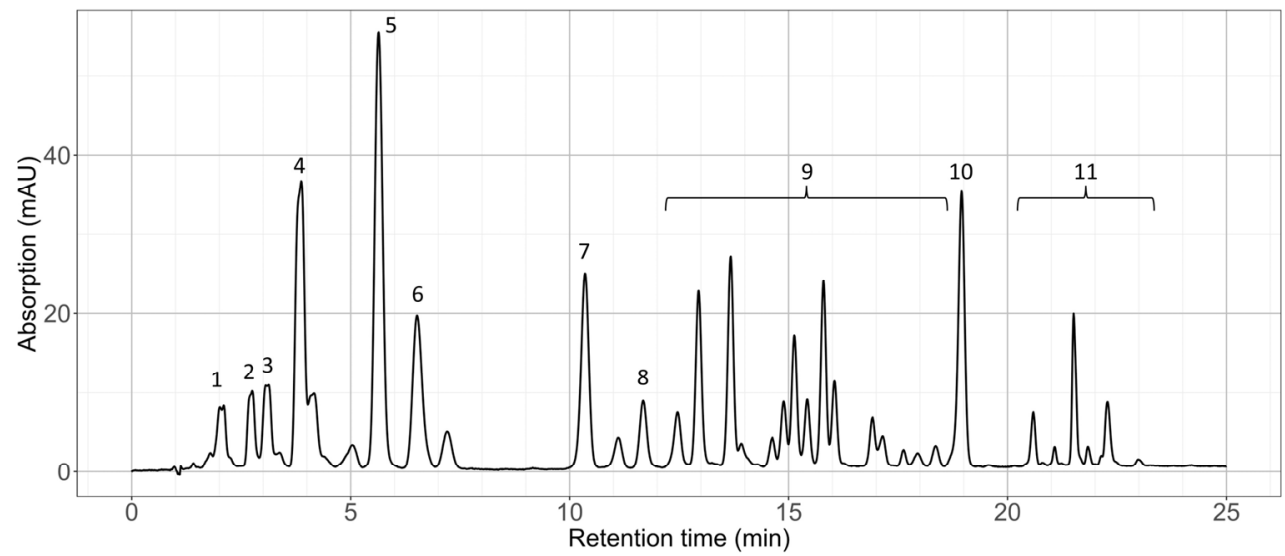

Figure 2. Absorption chromatogram at $450 \mathrm{~nm}$ of chromatographic separation before mass spectrometric analysis of the total pigment extract of C. terrestris WP154.1.

The detected pigments were $\mathrm{Chl} a$ and $\mathrm{Chl} b$, the PC included neoxanthin, violaxanthin, lutein, zeaxanthin and $\beta$-carotene, and the SC comprised astaxanthin, adonixanthin, canthaxanthin and echinenone (Table 1). Astaxanthin and adonixanthin were also detected in esterified forms. Monoesters (ME) were found for both and diesters (DE) only for astaxanthin. 
Table 1. Identified pigments of acetonic extract of $C$. terrestris WP154.1 by HPLC-MS analysis.

\begin{tabular}{ccccc}
\hline & $\begin{array}{c}\text { Assigned } \\
\text { Substance }\end{array}$ & $\begin{array}{c}\text { Detected Mass } \\
(\mathbf{M}+\mathbf{H})^{+}\end{array}$ & $\begin{array}{c}\text { Theoretical Mass } \\
(\mathbf{M}+\mathbf{H})^{+}\end{array}$ & $\begin{array}{c}\text { Mass Error } \\
\text { (ppm) }\end{array}$ \\
\hline 1 & Neoxanthin/violaxanthin ${ }^{1}$ & 601.4242 & 601.4251 & 1.5 \\
2 & Astaxanthin & 597.3930 & 597.3938 & 1.3 \\
3 & Adonixanthin & 583.4343 & 583.4351 & 1.4 \\
4 & Lutein/zeaxanthin 1 & 569.4355 & 569.4353 & 0.4 \\
5 & Canthaxanthin & 565.4046 & 565.4040 & 1.1 \\
6 & Chlorophyll $b$ & 907.5218 & 907.5219 & 0.1 \\
7 & Chlorophyll $a$ & 893.5424 & 893.5426 & 0.2 \\
8 & Echinenone & 551.4238 & 551.4247 & \\
9 & Astaxanthin and & & & \\
10 & adonixanthin ME & & & \\
11 & B-carotene & 537.4441 & 537.4455 & \\
\hline
\end{tabular}

${ }_{1}^{1}$ co-eluting isomers.

\subsubsection{Fatty Acid Profile of Lipids}

For the quantification of the FA composition of $C$. terrestris, a representative sample of orange-colored biomass harvested at the end of a cultivation was analyzed. The measured values of the corresponding FA methyl esters (FAME) are shown in Figure 3. All saturated even-numbered FA between C14 and C22 were detected with different levels of unsaturation.
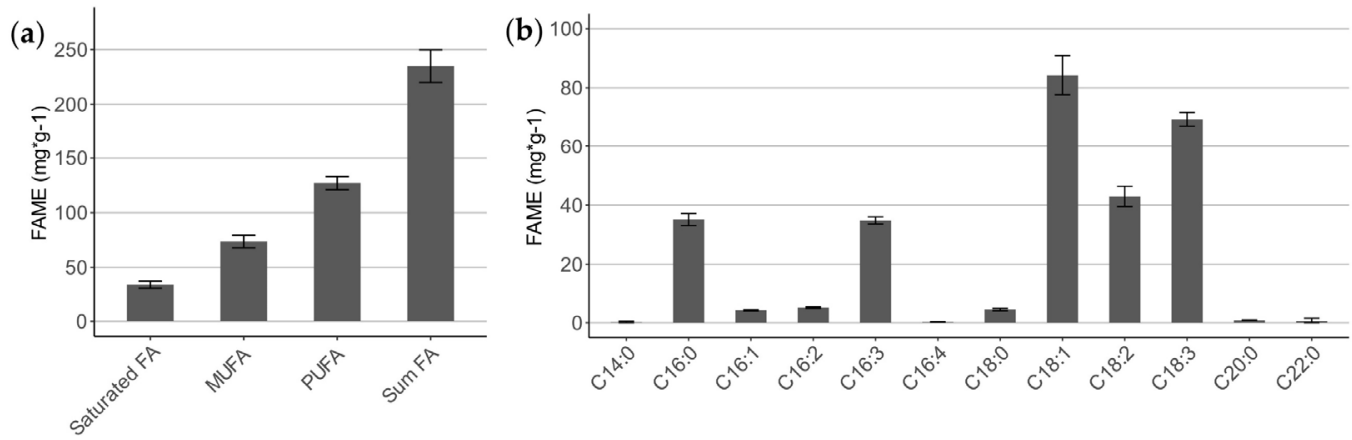

Figure 3. Fatty acid (FA) analysis of total lipids of $C$. terrestris as methyl esters. (a) Quantification of FA classified in degree of unsaturation; (b) quantification of all detected FA variants. MUFA, monounsaturated FA; PUFA, polyunsaturated FA.

In total, $234.9 \mathrm{mg} \cdot \mathrm{g}^{-1} \mathrm{FAME}$ were measured, of which $127.1 \mathrm{mg} \cdot \mathrm{g}^{-1}(54.1 \%)$ were polyunsaturated (PUFA), $73.7 \mathrm{mg} \cdot \mathrm{g}^{-1}(31.4 \%)$ monounsaturated (MUFA), and only $34.2 \mathrm{mg} \cdot \mathrm{g}^{-1}$ $(14.5 \%)$ of all FA were fully saturated (Figure 3a). The most abundant FA was the MUFA oleic acid (C18:1) with $70.3 \mathrm{mg} \cdot \mathrm{g}^{-1}$, which reflects $30.0 \%$ of all FAMEs (Figure $3 \mathrm{~b}$ ). The second-most quantified FAME was the PUFA $\alpha$-linoleic acid (C18:3) with $57.8 \mathrm{mg} \cdot \mathrm{g}^{-1}$, followed by $35.8 \mathrm{mg} \cdot \mathrm{g}^{-1}$ linoleic acid (C18:2).

\subsection{Carbon-Source Screening for Mixotrophic Growth}

Erlenmeyer flask experiments were done to determine suitable C-sources with the major focus to find accelerated mixotrophic biomass growth compared to an autotrophic reference process. The investigated C-sources were the hexoses fructose and glucose, the pentoses ribose and xylose, as well as acetate and glycerol. Growth curves expressed by optical density values at $600 \mathrm{~nm}\left(\mathrm{OD}_{600}\right)$ for each of the substrates including an autotrophic control culture were tracked for $37 \mathrm{~d}$ to identify the substrate for fastest mixotrophic growth (Figure 4 ). For comparison, the initial exponential growth rates $\left(\mu_{\max }\right)$ between the start of the experiment and day 10 were calculated. This time range was chosen, since all cultures 
still contained nitrate and supplemented C-source, and thus growth was not limited by nutrient starvation (data not shown).

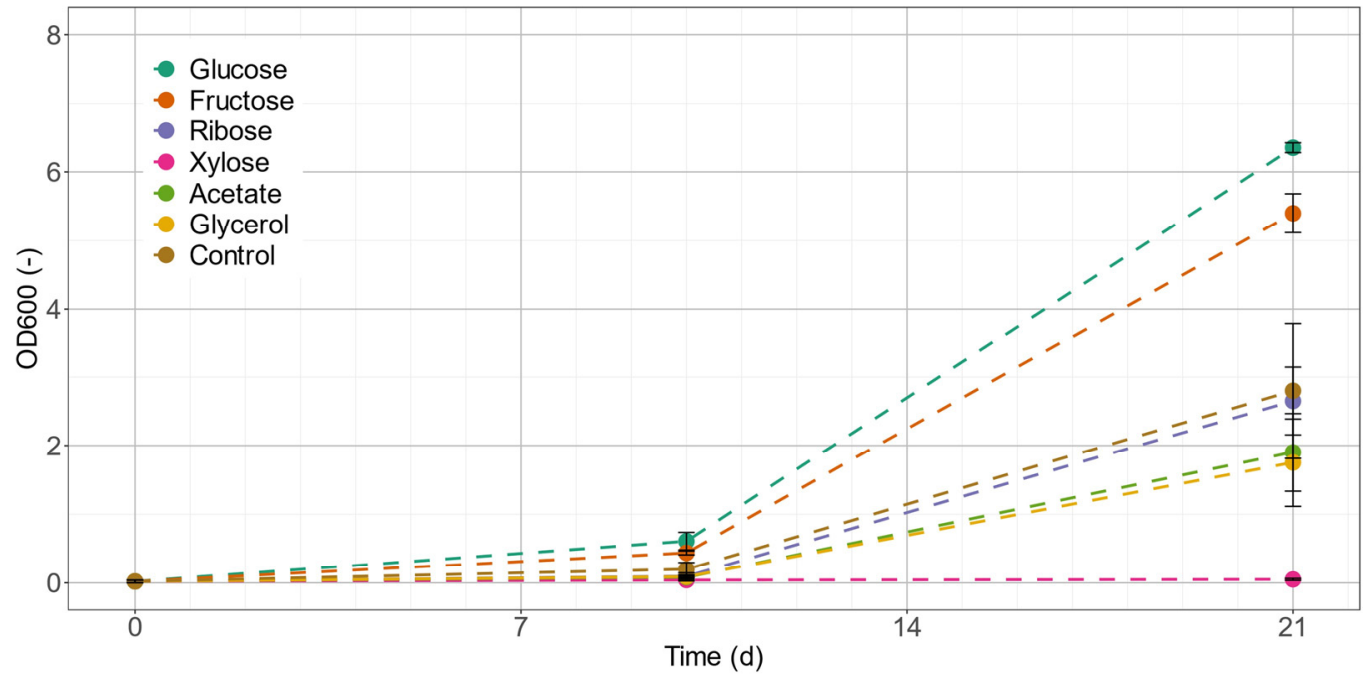

Figure 4. Growth curves of $C$. terrestris in Erlenmeyer flask cultures during initial growth screening with different $\mathrm{C}$-sources. The biomass content of the culture is expressed as measure of optical density at $600 \mathrm{~nm}\left(\mathrm{OD}_{600}\right)$.

The culture supplemented with glucose was growing fastest and resulted in a $\mu_{\text {max,glucose }}=0.34 \mathrm{~d}^{-1}$, followed by fructose (Table 2 ). The autotrophic control showed higher growth rates than cultures provided with ribose, acetate, glycerol and xylose. Biomass was increasing in all cultures for the first $21 \mathrm{~d}$, with glucose and fructose showing roughly the double $\mathrm{OD}_{600}$ values compared to the autotrophic control. Quantification of the C-source concentrations of glucose, fructose and acetate revealed values below the limit of detection after $21 \mathrm{~d}$ of cultivation. For ribose, xylose and glycerol, only approximately $10 \%$ of initial carbon content was metabolized after $21 \mathrm{~d}$ (data not shown). Thus, subsequent mixotrophic cultivations were conducted with (i) glucose, (ii) acetate, which is a common C-source in algae cultivations, and (iii) an autotrophic control.

Table 2. Growth evaluation of $C$. terrestris $C$-source screening. The listed parameters are optical density $\left(\mathrm{OD}_{600}\right)$ after 21 days of cultivation and exponential growth rate $\left(\mu_{\max }\right)$ during this period.

\begin{tabular}{cccccccc}
\hline & Glucose & Fructose & Ribose & Xylose & Acetate & Glycerol & Control \\
\hline OD $_{600}$ after & 6.35 & 5.40 & 2.65 & 0.05 & 1.90 & 1.75 & 2.80 \\
$21 \mathrm{~d}(-)$ & 0.34 & 0.31 & 0.16 & 0.07 & 0.14 & 0.15 & 0.23 \\
$\mu_{\max }\left(\mathrm{d}^{-1}\right)$ & 0.34 \\
\hline
\end{tabular}

\subsection{Scale-Up to 1.25 L Lab-Scale Photobioreactors}

To scale up the cultivations of $C$. terrestris, externally illuminated stirred PBRs were used. The experiments were conducted at two different nitrate levels of Bold's Basal Medium (BBM) with standard BBM and BBM with doubled nitrate content (2N-BBM). Both media were supplemented with glucose or acetate as mixotrophic C-sources. For comparison, autotrophic controls were done resulting in a total of six controlled and scalable PBR cultivations. The algal biomass trends expressed as $\mathrm{OD}_{600}$ for these cultivations are shown in Figure 5. 


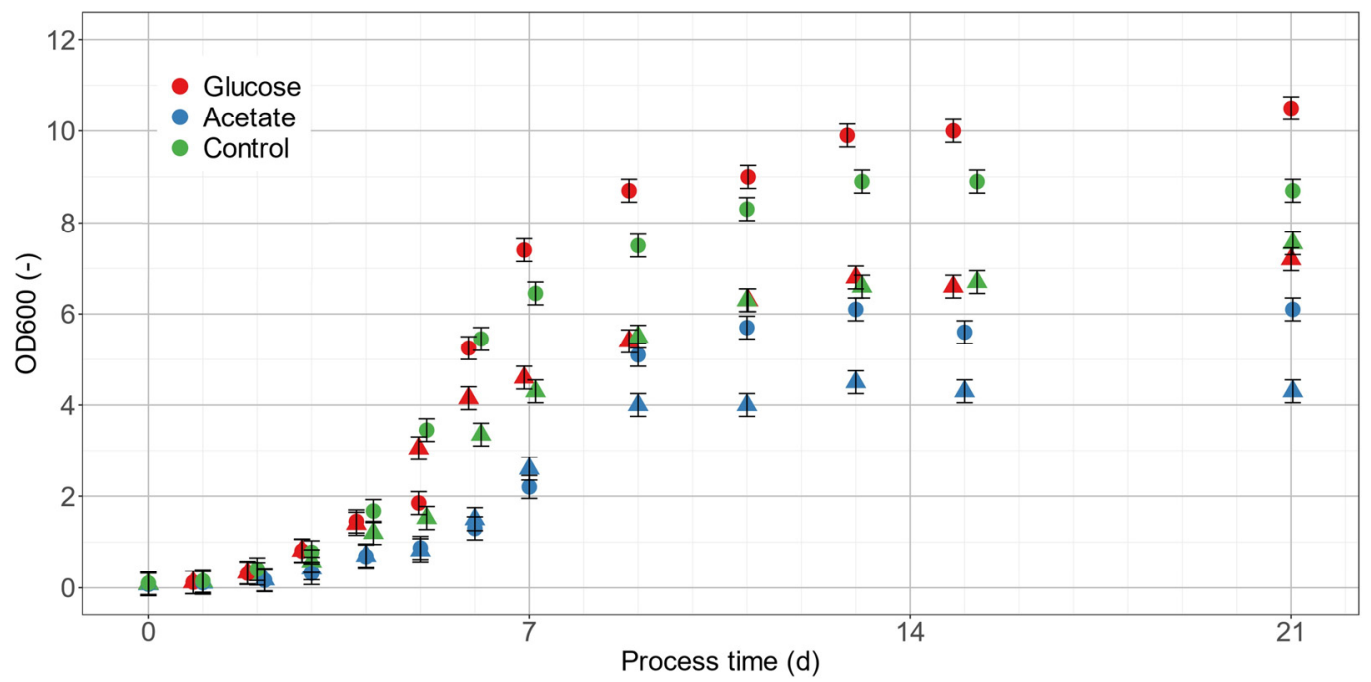

Figure 5. C. terrestris growth curves of PBR cultivations. Cultivations in BBM (filled triangles) and in 2N-BBM (fill circles) with supplemented C-sources glucose (red), acetate (blue), or control (green).

All cultures showed exponential growth from the beginning. During the first days of cultivation, the maximum growth rates $\left(\mu_{\max }\right)$ for BBM and $2 \mathrm{~N}$-BBM were highest in cultures containing glucose. The average $\mu_{\max }$ was $0.72 \mathrm{~d}^{-1}$ and $0.76 \mathrm{~d}^{-1}$, respectively. These were closely followed by the autotrophic controls with $0.63 \mathrm{~d}^{-1}$ and $0.68 \mathrm{~d}^{-1}$ for BBM and 2N-BBM, respectively. Both bioreactors containing acetate showed reduced $\mu_{\max }$ of $0.56 \mathrm{~d}^{-1}$ and $0.55 \mathrm{~d}^{-1}$. After a process time of $7 \mathrm{~d}$, the nitrate was completely consumed in all cultivations, which led to reduced growth rates (Table 3). From this time on, SC accumulated in the cells. $\mathrm{OD}_{600}$ values in this phase were still increasing to maximum $\mathrm{OD}_{600}$ values of about 7.5 for $\mathrm{BBM}$ and 10.0 for $2 \mathrm{~N}-\mathrm{BBM}$. Acetate in the medium reduced the final $\mathrm{OD}_{600}$ of the cultures to approximately 4.3 and 6.1, respectively.

Extracted pigments were individually quantified and subsequently grouped in the three categories Chl, PC and SC (Figure 6 and Supplementary Table S1). PBR cultivations with 2N-BBM gave more total pigments than with BBM (Figure 6a). The highest pigmentproducing culture was the $2 \mathrm{~N}-\mathrm{BBM}$ autotrophic control with $31.34 \mathrm{mg} \cdot \mathrm{L}^{-1}$ of total pigments concentration. The lowest-producing run of all experiments was BBM supplemented with acetate, with only $8.42 \mathrm{mg} \cdot \mathrm{L}^{-1}$. The average pigment composition for Chl, PC and SC was approx. $61 \pm 5 \%, 14 \pm 3 \%$ and $25 \pm 5 \%$, respectively. After having a closer look on the volumetric SC content (Figure $6 \mathrm{~b}$ ), the $2 \mathrm{~N}-\mathrm{BBM}$ acetate run showed highest overall values with $6.39 \mathrm{mg} \cdot \mathrm{L}^{-1}$, which was slightly more than the control $\left(6.14 \mathrm{mg} \cdot \mathrm{L}^{-1}\right) .2 \mathrm{~N}-\mathrm{BBM}$ runs had more volumetric SC content with the exception of BBM glucose, which was overall third highest with $5.53 \mathrm{mg} \cdot \mathrm{L}^{-1} \mathrm{SC}$. Lowest SC accumulating culture was BBM containing acetate $\left(1.99 \mathrm{mg} \cdot \mathrm{L}^{-1}\right)$. Concerning adonixanthin, the maximum concentration of $1.96 \mathrm{mg} \cdot \mathrm{L}^{-1}$ was detected in $2 \mathrm{~N}-\mathrm{BBM}$ with acetate, followed by the $2 \mathrm{~N}-\mathrm{BBM}$ control $\left(1.64 \mathrm{mg} \cdot \mathrm{L}^{-1}\right)$. Relative ratios of the SC astaxanthin, adonixanthin, canthaxanthin and echinenone of all cultivations were calculated as $46 \pm 5 \%, 28 \pm 2 \%, 23 \pm 5 \%$ and $2 \pm 2 \%$.

For evaluating the productivities of all SC and in particular adonixanthin, the corresponding volumetric (r) and specific production rates (q) were calculated (Table 3). After $7 \mathrm{~d}$, nitrate was consumed and the SC accumulation phase started until final harvest after $21 \mathrm{~d}$. This resulted in a maximum value of $\mathrm{r}_{\mathrm{SC}}$ for the $2 \mathrm{~N}-\mathrm{BBM}$ acetate culture with $0.43 \mathrm{mg} \cdot \mathrm{L}^{-1} \cdot \mathrm{d}^{-1}$. For adonixanthin, the highest volumetric $\left(\mathrm{r}_{\text {adonixanthin }}\right)$ and specific production rates (qadonixanthin) observed were $0.13 \mathrm{mg} \cdot \mathrm{L}^{-1} \cdot \mathrm{d}^{-1}$ and $0.06 \mathrm{mg} \cdot \mathrm{g}^{-1} \cdot \mathrm{d}^{-1}$ in the $2 \mathrm{~N}-\mathrm{BBM}$ acetate culture after stress induction. 
(a)

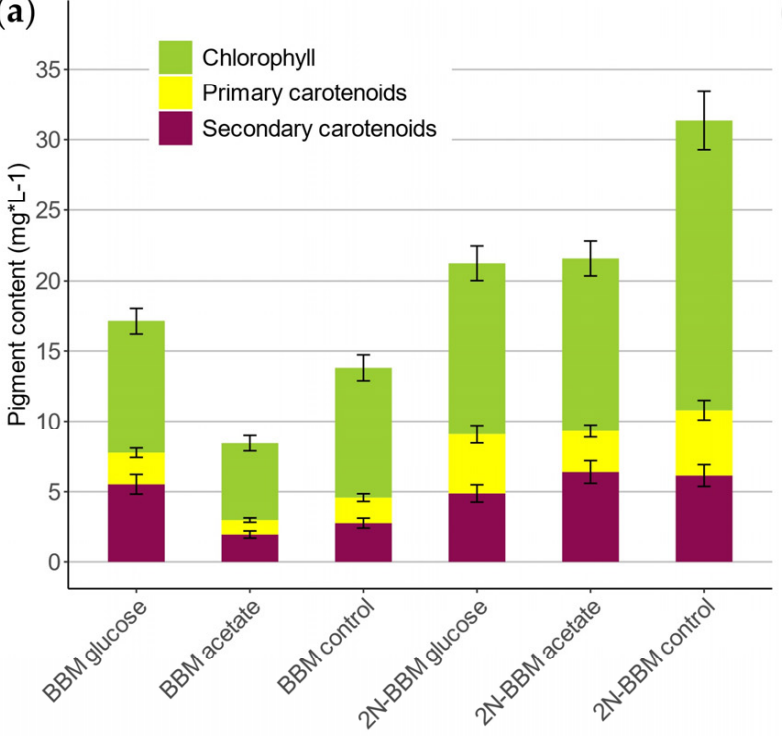

(b)

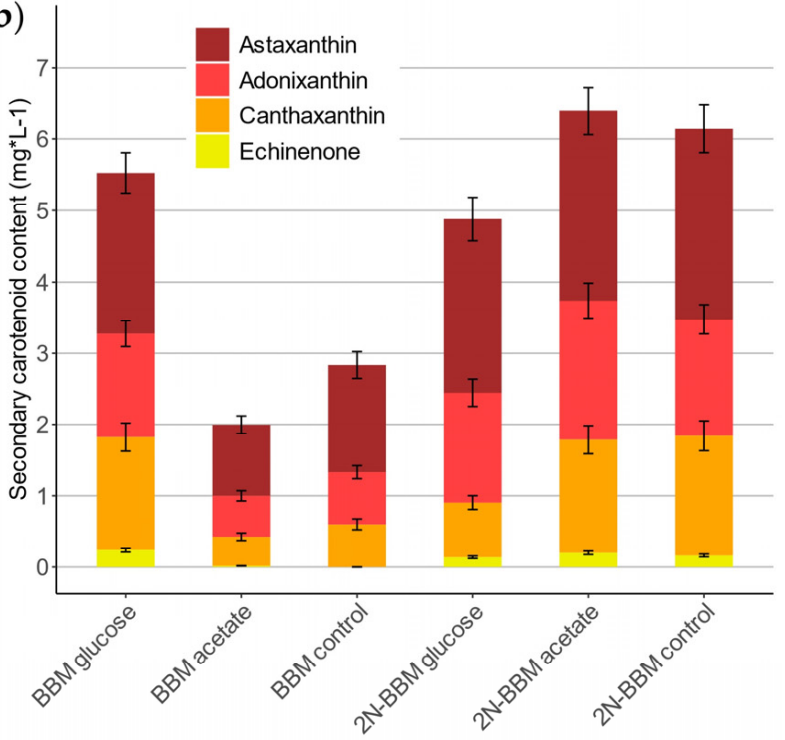

Figure 6. Quantification of pigment content after PBR cultivations of C. terrestris. (a) Total volumetric content of the pigments Chl, PC, SC; (b) volumetric content of SC astaxanthin, adonixanthin, canthaxanthin and echinenone.

Table 3. Growth and productivity assessment of $C$. terrestris WP154.1 PBR cultivations. The list shows exponential growth rate $\left(\mu_{\max }\right)$, average linear growth rate during limitation phase $\left(\mu_{\text {limitation }}\right)$, volumetric production rate of $\mathrm{SC}\left(\mathrm{r}_{\mathrm{SC}}\right)$ and adonixanthin $\left(\mathrm{r}_{\text {adonixanthin }}\right)$, and specific production rate of SC ( $\mathrm{q}_{\mathrm{SC}}$ ) and adonixanthin ( $\mathrm{q}_{\text {adonixanthin }}$ ). Growth phase was between 0 to $7 \mathrm{~d}$ and the limitation phase lasted from 7 until $21 \mathrm{~d}$.

\begin{tabular}{cccccccc}
\hline & Interval (d) & Glucose & $\begin{array}{c}\text { BBM } \\
\text { Acetate }\end{array}$ & Control & Glucose & $\begin{array}{c}\text { 2N-BBM } \\
\text { Acetate }\end{array}$ & Control \\
\hline$\mu_{\max }\left(\mathrm{d}^{-1}\right)$ & $0-7$ & $0.717 \pm 0.089$ & $0.561 \pm 0.070$ & $0.626 \pm 0.078$ & $0.757 \pm 0.094$ & $0.554 \pm 0.069$ & $0.681 \pm 0.085$ \\
$\mu_{\text {limitation }}\left(\mathrm{d}^{-1}\right)$ & $7-21$ & $0.111 \pm 0.013$ & $0.117 \pm 0.014$ & $0.126 \pm 0.015$ & $0.100 \pm 0.012$ & $0.197 \pm 0.024$ & $0.096 \pm 0.012$ \\
\hline $\mathrm{r}_{\mathrm{SC}}$ & $0-7$ & $0.184 \pm 0.023$ & $0.042 \pm 0.005$ & $0.035 \pm 0.004$ & $0.178 \pm 0.022$ & $0.047 \pm 0.005$ & $0.127 \pm 0.015$ \\
$\left(\mathrm{mg} \cdot \mathrm{L}^{-1} \cdot \mathrm{d}^{-1}\right)$ & $7-21$ & $0.302 \pm 0.037$ & $0.121 \pm 0.015$ & $0.182 \pm 0.022$ & $0.259 \pm 0.032$ & $0.432 \pm 0.054$ & $0.374 \pm 0.046$ \\
$\mathrm{q}_{\mathrm{SC}}$ & $0-7$ & $0.184 \pm 0.023$ & $0.070 \pm 0.008$ & $0.056 \pm 0.007$ & $0.242 \pm 0.030$ & $0.087 \pm 0.010$ & $0.137 \pm 0.017$ \\
$\left(\mathrm{mg} \cdot \mathrm{g}^{-1} \cdot \mathrm{d}^{-1}\right)$ & $7-21$ & $0.123 \pm 0.015$ & $0.067 \pm 0.008$ & $0.072 \pm 0.009$ & $0.097 \pm 0.012$ & $0.188 \pm 0.023$ & $0.128 \pm 0.016$ \\
\hline $\mathrm{r}_{\text {adonixanthin }}$ & $0-7$ & $0.046 \pm 0.005$ & $0.011 \pm 0.001$ & $0.005 \pm 0.000$ & $0.049 \pm 0.006$ & $0.018 \pm 0.002$ & $0.056 \pm 0.007$ \\
$\left(\mathrm{mg} \cdot \mathrm{L}^{-1} \cdot \mathrm{d}^{-1}\right)$ & $7-21$ & $0.080 \pm 0.010$ & $0.034 \pm 0.004$ & $0.049 \pm 0.006$ & $0.085 \pm 0.010$ & $0.130 \pm 0.016$ & $0.089 \pm 0.011$ \\
$\mathrm{q}_{\mathrm{adonixanthin}}$ & $0-7$ & $0.046 \pm 0.005$ & $0.019 \pm 0.002$ & $0.009 \pm 0.001$ & $0.067 \pm 0.008$ & $0.034 \pm 0.004$ & $0.060 \pm 0.007$ \\
$\left(\mathrm{mg} \cdot \mathrm{g}^{-1} \cdot \mathrm{d}^{-1}\right)$ & $7-21$ & $0.033 \pm 0.004$ & $0.019 \pm 0.002$ & $0.019 \pm 0.002$ & $0.032 \pm 0.004$ & $0.056 \pm 0.007$ & $0.030 \pm 0.003$ \\
\hline
\end{tabular}

\section{Discussion}

\subsection{Morphological and Physiological Characterization}

The green algal strain WP154.1 was identified as Coelastrella terrestris (Chlorophyta, Scenedesmaceae) by molecular means. Light microscopical examinations confirmed that cytomorphological characteristics were in agreement with previous descriptions $[23,30]$. The extracted pigments of orange-colored biomass revealed the presence of the rare SC adonixanthin. After lipid extraction and quantification, more than $54 \%$ of FA were polyunsaturated, with less than $15 \%$ saturated. These values were also comparable to other reports of members of the genus Coelastrella [25].

This initial physiological characterization indicates great potential for future industrial use of $C$. terrestris WP154.1 for both, scalable adonixanthin and polyunsaturated FA production. Due to its climate, Iceland seems to be a promising origin of microbial strains useful for biotechnology, as recently shown for another green microalga [31]. 


\subsection{Prelimary Experiments and Scale up to Photobioreactors}

Axenic cultivation experiments started with a screening for suitable C-sources regarding accelerated mixotrophic biomass growth compared to autotrophic controls. Mixotrophy could solve the bottleneck for a future economically feasible process [32]. The C-sources fructose, glucose, ribose, xylose, acetate and glycerol were supplemented in Erlenmeyer flask experiments.

The hexoses glucose and fructose performed best concerning the growth rate $\mu_{\max }$, which was $48 \%$ and $34 \%$ higher than the autotrophic control. All other C-sources caused reduced growth in relation to the control. Acetate, a commonly used C-source for algae, was lowering $\mu_{\max }$ by $40 \%$. Ribose, xylose and glycerol were not metabolized by the cells, despite reports showing consumption by other green algal species $[6,33,34]$. Therefore, subsequent experiments were done with either (i) glucose addition for highest biomass growth rates, or (ii) acetate supply as the most common C-source for carotenoid production, and (iii) an autotrophic control.

The PBR cultivation processes were designed to autoinduce SC production after nitrate in the medium was consumed. Growth rates in PBR were essentially higher compared to Erlenmeyer flask experiments. Comparing the BBM autotrophic cultures in both scales, the growth rate of the PBR cultivation was raised by a factor of 2.7. This was reasoned to be due to the improved light availability and enhanced mass transfer of gaseous $\mathrm{CO}_{2}$ in the used stirred PBR $[3,35]$. In the PBR, highest growth rates were observed in mixotrophic cultivations with glucose. However, biomass content of the autotrophic control was not significantly lower during the nitrogen-limited phase. Acetate as a mixotrophic C-source reduced growth rates and final biomass concentration for both nitrate levels. Apparently, acetate caused additional stress in the form of osmotic pressure, which impaired algal growth [36]. After pigment quantification, the autotrophic $2 \mathrm{~N}-\mathrm{BBM}$ culture revealed the highest overall volumetric pigment content primarily caused by elevated $\mathrm{Chl}$ levels. This was due to lowered $\mathrm{Chl}$ production of microalgae during mixotrophic conditions in the other PBR experiments [37]. During the nitrogen starvation phase, Chl was degraded and SC accumulated, as reported for green algae capable of SC synthesis [38]. Although acetate did not show the highest values for biomass concentration, specific SC content was considerably increased, and thus volumetric SC amount was highest of all runs with $6.39 \mathrm{mg} \cdot \mathrm{L}^{-1}$ total SC and $1.96 \mathrm{mg} \cdot \mathrm{L}^{-1}(31 \%)$ adonixanthin. Adonixanthin was approx. a factor of 11 higher compared to a recently published study of the green alga T. minimum, accumulating adonixanthin to a maximum volumetric content of $0.179 \mathrm{mg} \cdot \mathrm{L}^{-1}$ [36]. After entering the nitrogen starvation phase, the volumetric $\mathrm{SC}$ and adonixanthin production rates in the acetate culture were boosted by a factor of 9.0 to $0.13 \mathrm{mg} \cdot \mathrm{L}^{-1} \cdot \mathrm{d}^{-1}$ and a factor of 6.9 to $0.06 \mathrm{mg} \cdot \mathrm{L}^{-1} \cdot \mathrm{d}^{-1}$, respectively. This increase was much higher compared to glucose and the autotrophic control and again ascribed to addition of acetate in the culture which applied osmotic stress. Furthermore, this explains why acetate is often the stress factor of choice, e.g., for SC production processes for astaxanthin [39]. Additionally, it is cheap and often a byproduct of industry, e.g., during plant biomass hydrolyzation [40]. This might be crucial for economic and sustainable production processes in the future. Surprisingly, Minyuk et al. reported that the closely related Coelastrella rubescens was not affected by osmotic stress caused by acetate [29].

\subsection{Biotechnological Potential of C. terrestris WP154.1}

Microalgal biomass or extracted components are regarded as high-value products for human health and nutrition [41]. Specific compounds show bioactivity and are already used as functional food or as pharmaceutics [42,43]. C. terrestris WP154.1 revealed high content of the rare keto-carotenoid adonixanthin which has reportedly great potential to treat cancer or protect against brain damage $[21,44]$. To further improve adonixanthin production rates, we recommend two-stage cultivations to apply osmotic stress right after the growth phase ends [45]. Another possibility for optimization could be triggering the 
cells to transform to the resting cell stage, similar to Haematococcus lacustris; however, this cell stage has not been reported for any Coelastrella species yet [39,46].

\section{Materials and Methods}

\subsection{Sampling, Strain Isolation and Cultivation Medium}

The microalga was collected in Iceland in the foreland of Sölheimjökull glacier from a small brook where macroscopic mucilaginous mats of reddish cyanobacteria dominated. The GPS position was N63 $31.890 \mathrm{~W} 19^{\circ} 22.081$ at approximately $120 \mathrm{~m}$ above sea level. The permission for collection in Iceland was granted by the National Energy Authority Orkustofnun, leyfisnúmer OS-2017_L020-01. Cells were isolated from field material by autotrophic cultivation at $15^{\circ} \mathrm{C}$ and $30-40 \mu \mathrm{mol} \mathrm{PAR} \cdot \mathrm{m}^{-2} \cdot \mathrm{s}^{-1}\left(14 \mathrm{~h} \mathrm{light} \cdot \mathrm{d}^{-1}\right)$ on $1.6 \%$ agar plates with Bold's Basal Medium (BBM), which contained $250 \mathrm{mg} \cdot \mathrm{L}^{-1}$ $\mathrm{NaNO}_{3}, 75 \mathrm{mg} \cdot \mathrm{L}^{-1} \mathrm{MgSO}_{4} \cdot 7 \mathrm{H}_{2} \mathrm{O}, 25 \mathrm{mg} \cdot \mathrm{L}^{-1} \mathrm{NaCl}, 75 \mathrm{mg} \cdot \mathrm{L}^{-1} \mathrm{~K}_{2} \mathrm{HPO}_{4}, 175 \mathrm{mg} \cdot \mathrm{L}^{-1}$ $\mathrm{KH}_{2} \mathrm{PO}_{4}, 25 \mathrm{mg} \cdot \mathrm{L}^{-1} \mathrm{CaCl}_{2} \cdot 2 \mathrm{H}_{2} \mathrm{O}$, and $1 \mathrm{~mL} \cdot \mathrm{L}^{-1}$ of $1000 \times$ trace metal mix with a composition of $8.82 \mathrm{~g} \cdot \mathrm{L}^{-1} \mathrm{ZnSO}_{4} \cdot 7 \mathrm{H}_{2} \mathrm{O}, 1.44 \mathrm{~g} \cdot \mathrm{L}^{-1} \mathrm{MnCl}_{2} \cdot 4 \mathrm{H}_{2} \mathrm{O}, 0.71 \mathrm{~g} \cdot \mathrm{L}^{-1} \mathrm{MoO}_{3}, 1.57 \mathrm{~g} \cdot \mathrm{L}^{-1}$ $\mathrm{CuSO}_{4} \cdot 5 \mathrm{H}_{2} \mathrm{O}, 0.49 \mathrm{~g} \cdot \mathrm{L}^{-1} \mathrm{Co}\left(\mathrm{NO}_{3}\right)_{2} \cdot 6 \mathrm{H}_{2} \mathrm{O}, 11.4 \mathrm{~g} \cdot \mathrm{L}^{-1} \mathrm{H}_{3} \mathrm{BO}_{3}, 50.0 \mathrm{~g} \cdot \mathrm{L}^{-1} \mathrm{Na}_{2} \mathrm{EDTA} \cdot 2 \mathrm{H}_{2} \mathrm{O}$, and $4.98 \mathrm{~g} \cdot \mathrm{L}^{-1} \mathrm{FeSO}_{4} \cdot 7 \mathrm{H}_{2} \mathrm{O}$ [47].

The unialgal culture WP154.2 was established by mechanical isolation of cell colonies with a sterile loop. Axenic cultures were established by a workflow utilizing fluorescenceactivated cell sorting combined with plate spreading [48].

\subsection{Strain Identification}

The strain identification of $C$. terrestris WP154.2 (accession number OM574907.1) was done by molecular means with an $18 \mathrm{~S}$ rDNA marker. The primers used for this were 18F2 (5'-AAC CTG GTT GAT CCT GCC AGT-3') and 18R2 (5'-TGA TCC TTC TGC AGG TTC ACC TAC G-3'), as described by [49]. The sequenced fragment with 1,067 bp length was submitted to the National Center for Biotechnology Information (NCBI). The closest blast hits in the database of NCBI were Coelastrella terrestris strain CCALA 476 (accession JX513882.1) and Coelastrella terrestris strain KZ-5-4-9 (accession number MK231276.1). Both hits showed $100 \%$ identity at a query cover of $99 \%$. The resulting phylogenetic tree was created by the NCBI tool via the neighbor joining method [50]. It shows calculated distances of related species in Supplementary Figure S1. The strain WP154.2 is clearly grouping within the genus Coelastrella. Its closest neighbors were Coelastrella terrestris strain CCALA 476 (accession JX513882.1) and Coelastrella terrestris strain KZ-5-4-9 (accession number MK231276.1).

\subsection{Light Microscopy}

For light microscopical observations, a CKX41 inverted microscope (Olympus, Tokyo, Japan) with 1000x total magnification, was equipped with an EOS 250D camera (Canon, Tokyo, Japan). The camera was operated via EOS utility software (Canon, Tokyo, Japan).

\subsection{Pigment Extraction, Identification and Quantification}

The whole procedure of pigment extraction, identification and quantification is described in detail elsewhere [36]. Briefly, total pigments were extracted in acetone by disrupting roughly $20 \mathrm{mg}$ lyophilized biomass between glass beads in a FastPrep-24 instrument (MP Biomedicals, Santa Ana, CA, USA). The acetonic extract was separated on a 1290 Infinity II LC System (Agilent Technologies, Santa Clara, CA, USA) equipped with an Acclaim C30, $3 \mu \mathrm{m}, 2.1 \mathrm{~mm} \times 100 \mathrm{~mm}$ column (Thermo Fisher Scientific, Waltham, MA, USA). The masses were detected by a $6545 \mathrm{LC} / \mathrm{Q}-\mathrm{TOF}$ mass spectrometer (Agilent Technologies, Santa Clara, CA, USA) operated in atmospheric pressure chemical ionization (APCI) positive mode. The pigments were separately identified by comparison of detected and theoretical masses in combination with characteristic spectral absorption of each substance in agreement to literature [51]. Carotenoid mono- and diesters were assigned to adonixanthin and astaxanthin according to the characteristic absorption spectra of the 
respective unesterified form [52]. Astaxanthin was quantified on a Vanquish Flex HPLC system with DAD at $450 \mathrm{~nm}$ (Thermo Fisher Scientific, Waltham, MA, USA) with standard calibration. All other carotenoids were reference to astaxanthin at $450 \mathrm{~nm}$ [36]. Chlorophyll $a$ and $b$ were analyzed photometrically [53].

\subsection{Lipid Extraction, Transesterification and Quantification of Fatty Acids}

The workflow for quantifying fatty acids as methyl esters was done according to [36]. About $50 \mathrm{mg}$ dried biomass was extracted for lipids with a chloroform-methanol solvent. After transesterification in a methanol-hydrochloric acid mixture, the sample was injected to a 7890A/5975C GC-MS system (Agilent Technologies, Santa Clara, CA, USA) equipped with a CTC Combi PAL autosampler. Identification was done by a reference library and quantification via flame ionization detector. Calibration was achieved by the standard substances methyl palmitate (C16:0), methyl stearate (C18:0) and methyl arachidate (C20:0) (Sigma-Aldrich, St. Louis, MO, USA). Three independent biomass samples were treated for GC-MS quantification.

\subsection{C-Source Screening}

The experiments were conducted in $250 \mathrm{~mL}$ Erlenmeyer flasks. Every flask contained $50 \mathrm{~mL}$ standard $\mathrm{BBM}$ with $250 \mathrm{mg} \cdot \mathrm{L}^{-1} \mathrm{NaNO}_{3}$ at $\mathrm{pH}$ 7.0. Additional C-sources fructose, glucose, ribose, xylose, acetate and glycerol were added to the final concentration of $1.0 \mathrm{~g} \cdot \mathrm{L}^{-1}$ before autoclaving. After sterilization, the vitamins were added via $0.22 \mu \mathrm{m}$ syringe filter. All flasks were inoculated with $2 \mathrm{~mL}$ preculture grown in BBM in the middle of the exponential growth phase with $\mathrm{OD}_{600}$ about 0.5 . The flasks were placed in a Minitron incubation shaker (Infors, Basel, Switzerland) at $20^{\circ} \mathrm{C}, 150 \mathrm{rpm}$ ( $25 \mathrm{~mm}$ amplitude) with $3 \% \mathrm{CO}_{2}$-enriched atmosphere. The provided illumination expressed as photon flux density (PPFD) was $30 \mu \mathrm{mol} \mathrm{PAR} \cdot \mathrm{m}^{-2} \cdot \mathrm{s}^{-1}$ for $14 \mathrm{~h}$ light $\cdot \mathrm{d}^{-1}$. Samples were taken after 10 and $21 \mathrm{~d}$. The biomass content was estimated in $1 \mathrm{~mL}$ cuvettes on a Nanodrop One photometer (Thermo Fisher Scientific, Waltham, MA, USA) by absorption measurements at $600 \mathrm{~nm}$ wavelength. Then, $1 \mathrm{~mL}$ aliquots were centrifuged, and the supernatant was stored separately for subsequent $\mathrm{C}$-source and nitrate concentration measurements. Every cultivation experiment was carried out in biological duplicates and the respective average values were used for data evaluation.

\subsection{Stirred Photobioreactor Cultivations}

For cultivations in stirred PBR, a Ralf multi-bioreactor system (Bioengineering, Wald, Switzerland) was used (Supplementary Figure S2). The glass vessel had 2.0 L total volume with an inner diameter of $95 \mathrm{~mm}$. Light was provided from the outside through the glass jacket for heating and cooling. A $5 \mathrm{~m}$ warm-white LED light strip (Paulmann, Völksen, Germany) providing $960 \mathrm{~lm}$ via 100 single LED spots, was uniformly wrapped around the vessel. The reactor was equipped with two $55 \mathrm{~mm}$ turbine impellers, an EasyFerm plus $\mathrm{pH}$ probe (Hamilton, Bonaduz, Switzerland) and a ring sparger for gas supply. Gas was premixed by two separate type 4850 mass flow controllers connected to a 0254 operation unit (Brooks Instruments, Hatfield, PA, USA).

Standard BBM, or BBM with double nitrate content (2N-BBM), was directly used or supplemented with $33.3 \mathrm{mmol} \cdot \mathrm{L}^{-1}$ carbon in form of glucose $\left(\mathrm{C}_{6} \mathrm{H}_{12} \mathrm{O}_{6}\right)$ or acetate $\left(\mathrm{CH}_{3} \mathrm{COONa}\right)$. Then, a $1.25 \mathrm{~L}$ prepared medium was filled into the PBR prior to autoclaving. After that, vitamins were injected aseptically via $0.22 \mu \mathrm{m}$ syringe filter and a septum. The gas was mixed to $3.0 \% \mathrm{CO}_{2}$-enriched air and provided at a rate of $0.1 \mathrm{vvm}$. Cultivation temperate was $20^{\circ} \mathrm{C}$ and the stirrer agitated with $300 \mathrm{rpm}$. The provided PPFD in the center of the reactor was about $170 \mu \mathrm{mol} \mathrm{PAR} \cdot \mathrm{m}^{-2} \cdot \mathrm{s}^{-1}$ during the first $72 \mathrm{~h}$ of the process and then changed to $850 \mu \mathrm{mol} \mathrm{PAR} \cdot \mathrm{m}^{-2} \cdot \mathrm{s}^{-1}$, measured by an US-SQS/L sensor (Walz, Ulm, Germany) in a cell-free medium. The light was automatically simulating a $14 \mathrm{~h} \mathrm{light} \cdot \mathrm{d}^{-1}$ cycle. The $\mathrm{pH}$ was set to $6.3 \pm 0.05$ via automatic addition of $1 \mathrm{~mol} \cdot \mathrm{L}^{-1} \mathrm{Na}_{2} \mathrm{CO}_{3}$ prior to inoculation. Roughly $20 \mathrm{~mL}$ preculture, also grown in BBM, was added via a syringe 
and septum. The final $\mathrm{OD}_{600}$ after inoculation was between 0.02 and 0.04 . The experiment was started when the respective culture reached $\mathrm{OD}_{600}$ of $0.10 \pm 0.01$ to avoid possible preculture differences. Regular samples for $\mathrm{OD}_{600}(1 \mathrm{~mL}$ cuvettes on a Nanodrop One photometer (Thermo Fisher Scientific, Waltham, MA, USA)) and nitrate quantification were drawn on days $0,1,2,3,4,5,6,7,9,11,13,15$ and 21. Then, $20 \mathrm{~mL}$ biomass samples for pigment quantification were harvested by centrifugation and lyophilized on days 7, 11, 15 and 21. Specific exponential growth rate $\left(\mu_{\max }\right)$ was calculated with $\mathrm{OD}_{600}$ at a certain process time $\left(\mathrm{OD}_{600, t}\right)$ and compared to the initial value $\left(\mathrm{OD}_{600, t=0}\right)$ (Equation (1)):

$$
\mu_{\max }=\ln \left(\mathrm{OD}_{600, t} / \mathrm{OD}_{600, t=0}\right) / t
$$

The average volumetric production rate of a product $\left(r_{\mathrm{P}}\right)$ between two time points $\left(t_{1}\right.$ and $t_{2}$ ) was calculated after product concentration measurements of the product of interest at the same time points $\left(c_{P, 1}\right.$ and $\left.c_{P, 2}\right)$ :

$$
r_{\mathrm{P}}=\left(c_{\mathrm{P}, 2}-c_{\mathrm{P}, 1}\right) /\left(t_{2}-t_{1}\right)
$$

and for specific production rate $\left(q_{\mathrm{P}}\right)$, the biomass $(X)$ was considered additionally (Equation (3)):

$$
q_{\mathrm{P}}=r_{\mathrm{P}} / X
$$

\subsection{Quantification of Carbon-Source}

The supernatant was analyzed on an UltiMate 3000 HPLC system with diode array detector (DAD) (Thermo Fisher Scientific, Waltham, MA, USA) by an Aminex HPX-87 H column (Bio-Rad Laboratories, Hercules, CA, USA). The method was recently described in detail [54]. Calibration standards of all investigated C-sources (glucose, fructose, ribose, xylose, acetate and glycerol) were freshly prepared of pure substances (Sigma-Aldrich, St. Louis, MO, USA), diluted and analyzed accordingly.

\subsection{Nitrate Quantification}

The nitrate content in the cultures were determined in the supernatant after centrifugation of the samples. The exact method was published elsewhere [36]. A Dionex ICS-6000 ion chromatography system (Thermo Fisher Scientific, Waltham, MA, USA) equipped with an IonPac AS11 and guard column (Thermo Fisher Scientific, Waltham, MA, USA) was used. Detection was done via a conductivity detector unit (Thermo Fisher Scientific, Waltham, MA, USA). Quantification was possible via calibration of nitrate standards (Sigma-Aldrich, St. Louis, MO, USA).

Supplementary Materials: The following are available online at https:/ / www.mdpi.com/article/ 10.3390/md20030175/s1, Table S1: Biomass concentration and volumetric and specific pigment and secondary carotenoid concentrations of $1.25 \mathrm{~L}$ lab-scale photobioreactor cultivations of $C$. terrestris; Figure S1: Phylogenetic tree of the strain Coelastrella terrestris WP154.2 (highlighted in yellow, accession number OM574907.1). The analysis is based on the 1067 nucleotides of the nuclear 18S rDNA fragment. It was drawn by the NCBI tool for showing distances to related species by the neighbor joining tree method. Type strains are highlighted in green. Closest relatives of WP154.2 were Coelastrella terrestris strain CCALA 476 (accession JX513882.1) and Coelastrella terrestris strain KZ-5-4-9 (accession number MK231276.1); Figure S2: The externally illuminated stirred tank photobioreactor (PBR) system used for 1.25 L lab-scale cultivation of C. terrestris WP154.2.

Author Contributions: Conceptualization, P.D., J.K. and O.S.; methodology, P.D., R.K., M.K. and D.R.; validation, P.D. and J.K.; formal analysis, P.D., R.K. and M.K.; investigation, P.D. and M.K.; resources, D.R.; data curation, P.D. and J.K.; writing-original draft preparation, P.D.; writing-review and editing, R.K., J.K., D.R. and O.S.; visualization, P.D.; supervision, P.D. and O.S.; project administration, O.S.; funding acquisition, D.R. and O.S. All authors have read and agreed to the published version of the manuscript. 
Funding: TU Wien is funding the doctoral college bioactive. We thank Interreg for funding Project Plastocyan ATCZ260. The Austrian Science Fund (FWF) is funding P 29959 and P 34073 to D.R. Open Access Funding by the Austrian Science Fund (FWF).

Institutional Review Board Statement: Not applicable.

Informed Consent Statement: Not applicable.

Data Availability Statement: The data presented in this study are available on request from the corresponding author.

Acknowledgments: The authors appreciate the help of Irene Tomico-Cuenca for molecular strain identification. Ewald Srebotnik is thanked for GC-MS measurements. Open Access Funding by the Austrian Science Fund (FWF).

Conflicts of Interest: The authors declare no conflict of interest.

\section{References}

1. Singh, J.; Saxena, R.C. An Introduction to Microalgae: Diversity and Significance. Diversity and Significance. Handb. Mar. Microalgae Biotechnol. Adv. 2015, 11-24. [CrossRef]

2. Henriquez, V.; Escobar, C.; Galarza, J.; Gimpel, J. Carotenoids in Microalgae. Carotenoids Nat. 2016, 79, 219-237. [CrossRef]

3. Doppler, P.; Spadiut, O. Introduction to autotrophic cultivation of microalgae in photobioreactors. In The Autotrophic Biorefinery; Kourist, R., Schmidt, S., Eds.; De Gruyter: Berlin, Germany, 2021; pp. 113-130. [CrossRef]

4. $\mathrm{Hu}$, J.; Nagarajan, D.; Zhang, Q.; Chang, J.S.; Lee, D.J. Heterotrophic cultivation of microalgae for pigment production: A review. Biotechnol. Adv. 2018, 36, 54-67. [CrossRef] [PubMed]

5. Khan, M.I.; Shin, J.H.; Kim, J.D. The promising future of microalgae: Current status, challenges, and optimization of a sustainable and renewable industry for biofuels, feed, and other products. Microb. Cell Fact. 2018, 17, 36. [CrossRef] [PubMed]

6. Yang, S.; Liu, G.; Meng, Y.; Wang, P.; Zhou, S.; Shang, H. Utilization of xylose as a carbon source for mixotrophic growth of Scenedesmus obliquus. Bioresour. Technol. 2014, 172, 180-185. [CrossRef]

7. Lowrey, J.; Brooks, M.S.; McGinn, P.J. Heterotrophic and mixotrophic cultivation of microalgae for biodiesel production in agricultural wastewaters and associated challenges-a critical review. J. Appl. Phycol. 2015, 27, 1485-1498. [CrossRef]

8. Molino, A.; Iovine, A.; Casella, P.; Mehariya, S.; Chianese, S.; Cerbone, A.; Rimauro, J.; Musmarra, D. Microalgae characterization for consolidated and new application in human food, animal feed and nutraceuticals. Int. J. Environ. Res. Public Health 2018, 15, 2436. [CrossRef]

9. Varshney, P.; Mikulic, P.; Vonshak, A.; Beardall, J.; Wangikar, P.P. Extremophilic micro-algae and their potential contribution in biotechnology. Bioresour. Technol. 2015, 184, 363-372. [CrossRef] [PubMed]

10. Yan, N.; Fan, C.; Chen, Y.; Hu, Z. The potential for microalgae as bioreactors to produce pharmaceuticals. Int. J. Mol. Sci. 2016, 17, 962. [CrossRef]

11. Kumar, J.; Singh, D.; Tyagi, M.B.; Kumar, A. Applications in Biotechnology. In Cyanobacteria; Mishra, A.K., Tiwari, D.N., Rai, A.N., Eds.; Academic Press: Cambrige, MA, USA, 2019; pp. 327-346. [CrossRef]

12. Maoka, T. Carotenoids as natural functional pigments. J. Nat. Med. 2020, 74, 1-16. [CrossRef]

13. Demmig-Adams, B.; Stewart, J.J.; López-Pozo, M.; Polutchko, S.K.; Adams, W.W. Zeaxanthin, a Molecule for Photoprotection in Many Different Environments. Molecules 2020, 25, 5825. [CrossRef]

14. Christaki, E.; Bonos, E.; Giannenasa, I.; Florou-Paneria, P. Functional properties of carotenoids originating from algae. J. Sci. Food Agric. 2013, 93, 5-11. [CrossRef]

15. Varela, J.C.; Pereira, H.; Vila, M.; León, R. Production of carotenoids by microalgae: Achievements and challenges. Photosynth. Res. 2015, 125, 423-436. [CrossRef]

16. Rico, M.; González, A.G.; Santana-Casiano, M.; González-Dávila, M.; Pérez-Almeida, N.; Suarez de Tangil, M. Production of Primary and Secondary Metabolites Using Algae. In Prospects and Challenges in Algal Biotechnology; Springer: Berlin/Heidelberg, Germany, 2017; pp. 1-326. [CrossRef]

17. Ambati, R.R.; Gogisetty, D.; Aswathanarayana, R.G.; Ravi, S.; Bikkina, P.N.; Bo, L.; Yuepeng, S. Industrial potential of carotenoid pigments from microalgae: Current trends and future prospects. Crit. Rev. Food Sci. Nutr. 2019, 59, 1880-1902. [CrossRef]

18. Sun, X.M.; Ren, L.J.; Zhao, Q.Y.; Ji, X.J.; Huang, H. Microalgae for the production of lipid and carotenoids: A review with focus on stress regulation and adaptation. Biotechnol. Biofuels 2018, 11, 272. [CrossRef] [PubMed]

19. Lu, Q.; Li, H.; Zou, Y.; Liu, H.; Yang, L. Astaxanthin as a microalgal metabolite for aquaculture: A review on the synthetic mechanisms, production techniques, and practical application. Algal Res. 2021, 54, 102178. [CrossRef]

20. Naguib, Y.M.A. Antioxidant activities of astaxanthin and related carotenoids. J. Agric. Food Chem. 2000, 48, 1150-1154. [CrossRef]

21. Iwata, S.; Imai, T.; Shimazawa, M.; Ishibashi, T.; Hayashi, M.; Hara, H.; Nakamura, S. Protective effects of the astaxanthin derivative, adonixanthin, on brain hemorrhagic injury. Brain Res. 2018, 1698, 130-138. [CrossRef] [PubMed]

22. Maoka, T.; Yasui, H.; Ohmori, A.; Tokuda, H.; Suzuki, N.; Osawa, A.; Shindo, K.; Ishibashi, T. Anti-oxidative, anti-tumorpromoting, and anti-carcinogenic activities of adonirubin and adonixanthin. J. Oleo Sci. 2013, 62, 181-186. [CrossRef] 
23. Reisigl, H. Zur Systematik und Ökologie alpiner Bodenalgen. Osterr. Bot. Z. 1964, 111, 402-499. [CrossRef]

24. Hu, C.W.; Chuang, L.-T.; Yu, P.C.; Chen, C.N.N. Pigment production by a new thermotolerant microalga Coelastrella sp. F50. Food Chem. 2013, 138, 2071-2078. [CrossRef]

25. Minhas, A.K.; Hodgson, P.; Barrow, C.J.; Sashidhar, B.; Adholeya, A. The isolation and identification of new microalgal strains producing oil and carotenoid simultaneously with biofuel potential. Bioresour. Technol. 2016, 211, 556-565. [CrossRef] [PubMed]

26. Wang, Q.; Song, H.; Liu, X.; Liu, B.; Hu, Z.; Liu, G. Morphology and molecular phylogeny of coccoid green algae Coelastrella sensu lato (Scenedesmaceae, Sphaeropeales), including the description of three new species and two new varieties. J. Phycol. 2019, 55, 1290-1305. [CrossRef] [PubMed]

27. Goecke, F.; Noda, J.; Paliocha, M.; Gislerød, H.R. Revision of Coelastrella (Scenedesmaceae, Chlorophyta) and first register of this green coccoid microalga for continental Norway. World J. Microbiol. Biotechnol. 2020, 36, 149. [CrossRef]

28. Zaytseva, A.; Chekanov, K.; Zaytsev, P.; Bakhareva, D.; Gorelova, O.; Kochkin, D.; Lobakova, E. Sunscreen effect exerted by secondary carotenoids and mycosporine-like amino acids in the aeroterrestrial chlorophyte Coelastrella rubescens under high light and UV-A irradiation. Plants 2021, 10, 2601. [CrossRef]

29. Minyuk, G.; Chelebieva, E.; Chubchikova, I.; Dantsyuk, N.; Drobetskaya, I.; Sakhon, E.; Chekanov, K.; Solovchenko, A. Stress-induced secondary carotenogenesis in Coelastrella rubescens (Scenedesmaceae, Chlorophyta), a producer of value-added keto-carotenoids. Algae 2017, 32, 245-259. [CrossRef]

30. Tschaikner, A.; Ingolic, E.; \& Gärtner, G. Observations in a New Isolate of Coelastrella terrestris (Reisigl) Hegewald \& Hanagata (Chlorophyta, Scenedesmaceae) from Alpine Soil (Tyrol, Austria). Phyton B. Aires 2007, 46, 237-245.

31. Nicoletti, C.; Procházková, L.; Nedbalová, L.; Mócsai, R.; Altmann, F.; Holzinger, A.; Remias, D. Thorsmoerkia curvula gen. et spec. nov. (Trebouxiophyceae, Chlorophyta), a semi-terrestrial microalga from Iceland exhibits high levels of unsaturated fatty acids. $J$. Appl. Phycol. 2021, 33, 3671-3682. [CrossRef]

32. Zhang, T.Y.; Hu, H.Y.; Wu, Y.H.; Zhuang, L.L.; Xu, X.Q.; Wang, X.X.; Dao, G.H. Promising solutions to solve the bottlenecks in the large-scale cultivation of microalgae for biomass/bioenergy production. Renew. Sustain. Energy Rev. 2016, 60, 1602-1614. [CrossRef]

33. Pang, N.; Xie, Y.; Oung HM, O.; Sonawane, B.V.; Fu, X.; Kirchhoff, H.; Cousins, A.B.; Chen, S. Regulation and stimulation of photosynthesis of mixotrophically cultured Haematococcus pluvialis by ribose. Algal Res. 2019, 39, 101443. [CrossRef]

34. Zhang, L.; Zhang, C.; Liu, J.; Yang, N. A strategy for stimulating astaxanthin and lipid production in Haematococcus pluvialis by exogenous glycerol application under low light. Algal Res. 2020, 46, 101779. [CrossRef]

35. Socher, M.L.; Löser, C.; Schott, C.; Bley, T.; Steingroewer, J. The challenge of scaling up photobioreactors: Modeling and approaches in small scale. Eng. Life Sci. 2016, 16, 598-609. [CrossRef]

36. Doppler, P.; Kornpointner, C.; Halbwirth, H.; Remias, D.; Spadiut, O. Tetraedron minimum, first reported member of hydrodictyaceae to accumulate secondary carotenoids. Life 2021, 11, 107. [CrossRef]

37. Da Silva Ferreira, V.; Sant'Anna, C. Impact of culture conditions on the chlorophyll content of microalgae for biotechnological applications. World J. Microbiol. Biotechnol. 2017, 33, 20. [CrossRef] [PubMed]

38. Lemoine, Y.; Schoefs, B. Secondary ketocarotenoid astaxanthin biosynthesis in algae: A multifunctional response to stress. Photosynth. Res. 2010, 106, 155-177. [CrossRef] [PubMed]

39. Li, X.; Wang, X.; Duan, C.; Yi, S.; Gao, Z.; Xiao, C.; Agathos, S.N.; Wang, G.; Li, J. Biotechnological production of astaxanthin from the microalga Haematococcus pluvialis. Biotechnol. Adv. 2020, 43, 107602. [CrossRef]

40. Serna-Loaiza, S.; Zikeli, F.; Adamcyk, J.; Friedl, A. Towards a wheat straw biorefinery: Combination of Organosolv and Liquid Hot Water for the improved production of sugars from hemicellulose and lignin hydrolysis. Bioresour. Technol. Reports 2021, 14, 100667. [CrossRef]

41. Barkia, I.; Saari, N.; Manning, S.R. Microalgae for high-value products towards human health and nutrition. Mar. Drugs 2019, 17, 304. [CrossRef] [PubMed]

42. Guedes, A.C.; Amaro, H.M.; Malcata, F.X. Microalgae as sources of carotenoids. Mar. Drugs 2011, 9, 625-644. [CrossRef] [PubMed]

43. Iyer, G.; Nagle, V.; Gupte, Y.V.; Desai, S.; Iyer, M. Characterization of High Carotenoid Producing Coelastrella oocystiformis and its Anti-Cancer Potential. Int. J. Curr. Microbiol. Appl. Sci. 2015, 4, 527-536.

44. Tsuji, S.; Nakamura, S.; Maoka, T.; Yamada, T.; Imai, T.; Ohba, T.; Yako, T.; Hayashi, M.; Endo, K.; Saio, M.; et al. Antitumour effects of astaxanthin and adonixanthin on glioblastoma. Mar. Drugs 2020, 18, 474. [CrossRef] [PubMed]

45. Nagappan, S.; Devendran, S.; Tsai, P.C.; Dahms, H.U.; Ponnusamy, V.K. Potential of two-stage cultivation in microalgae biofuel production. Fuel 2019, 252, 339-349. [CrossRef]

46. Tschaikner, A.; Ingolić, E.; Stoyneva, M.P.; Gärtner, G. Autosporulation in the soil alga Coelastrella terrestris (Chlorophyta, Scenedesmaceae, Scenedesmoideae). Phytol. Balc. 2007, 13, 29-34.

47. Bolt's Basal Medium BBM. Available online: http:/ / cccryo.fraunhofer.de/sources/files/medien/BBM.pdf (accessed on 7 January 2022).

48. Doppler, P.; Kriechbaum, R.; Singer, B.; Spadiut, O. Make microalgal cultures axenic again-A fast and simple workflow utilizing fluorescence-activated cell sorting. J. Microbiol. Methods 2021, 186, 106256. [CrossRef]

49. Procházková, L.; Remias, D.; Řezanka, T.; Nedbalová, L. Ecophysiology of Chloromonas hindakii sp. Nov. (chlorophyceae), causing orange snow blooms at different light conditions. Microorganisms 2019, 7, 434. [CrossRef] [PubMed] 
50. Schoch, C.L.; Ciufo, S.; Domrachev, M.; Hotton, C.L.; Kannan, S.; Khovanskaya, R.; Leipe, D.; McVeigh, R.; O’Neill, K.; Robbertse, B.; et al. NCBI Taxonomy: A comprehensive update on curation, resources and tools. Database 2020, 2020, baaa062. [CrossRef] [PubMed]

51. Remias, D.; Pichrtová, M.; Pangratz, M.; Lütz, C.; Holzinger, A. Ecophysiology, secondary pigments and ultrastructure of Chlainomonas sp. (Chlorophyta) from the European Alps compared with Chlamydomonas nivalis forming red snow. FEMS Microbiol. Ecol. 2016, 92, fiw030. [CrossRef] [PubMed]

52. Remias, D.; Lütz, C. Characterisation of esterified secondary carotenoids and of their isomers in green algae: A HPLC approach. Arch. Hydrobiol. Suppl. Algol. Stud. 2007, 124, 85-94. [CrossRef]

53. Porra, R.J.; Thompson, W.A.; Kriedemann, P.E. Determination of accurate extinction coefficients and simultaneous equations for assaying chlorophylls $a$ and $b$ extracted with four different solvents: Verification of the concentration of chlorophyll standards by atomic absorption spectroscopy. Biochim. Biophys. Acta 1989, 975, 384-394. [CrossRef]

54. Doppler, P.; Gasser, C.; Kriechbaum, R.; Ferizi, A.; Spadiut, O. In Situ Quantification of Polyhydroxybutyrate in Photobioreactor Cultivations of Synechocystis sp. Using an Ultrasound-Enhanced ATR-FTIR Spectroscopy Probe. Bioengineering $2021,8,129$. [CrossRef] 